\title{
WestVirginiaUniversity
}

THE RESEARCH REPOSITORY @ WVU

Graduate Theses, Dissertations, and Problem Reports

2020

\section{Individual Differences in Social Decision-Making Preferences}

Kelly R. Smith

West Virginia University, ks0163@mix.wvu.edu

Follow this and additional works at: https://researchrepository.wvu.edu/etd

Part of the Developmental Psychology Commons

\section{Recommended Citation}

Smith, Kelly R., "Individual Differences in Social Decision-Making Preferences" (2020). Graduate Theses, Dissertations, and Problem Reports. 7915.

https://researchrepository.wvu.edu/etd/7915

This Thesis is protected by copyright and/or related rights. It has been brought to you by the The Research Repository @WVU with permission from the rights-holder(s). You are free to use this Thesis in any way that is permitted by the copyright and related rights legislation that applies to your use. For other uses you must obtain permission from the rights-holder(s) directly, unless additional rights are indicated by a Creative Commons license in the record and/ or on the work itself. This Thesis has been accepted for inclusion in WVU Graduate Theses, Dissertations, and Problem Reports collection by an authorized administrator of The Research Repository @ WVU. For more information, please contact researchrepository@mail.wvu.edu. 
Individual Differences in Social Decision-Making Preferences

Kelly Smith, B.A.

\author{
Thesis submitted \\ to the Eberly College of Arts and Sciences \\ at West Virginia University \\ in partial fulfillment of the requirements for the degree of \\ Master of Science \\ in \\ Psychology
}
JoNell Strough, Ph.D., Chair
Constance Toffle, Ph.D.
Barry Edelstein, Ph.D.

Department of Psychology

\title{
Morgantown, West Virginia 2020
}

Keywords: decision-making, age differences, gender differences, perceived ability, perceptions of aging

Copyright 2020 Kelly Smith 


\begin{abstract}
Individual Differences in Social Decision-Making Preferences
\end{abstract}

\title{
Kelly Smith
}

Most research on decision making to date has focused primarily on the individual decision maker and has not looked at social aspects of decision making. A review of decision making in older adults indicated that older adults rate their own decision-making competence as worse than younger adults, even though not all facets of decision making decline with age (Strough, Bruine de Bruin, \& Peters, 2015). Because of social roles that contribute to gender differences, women are theorized to be more interpersonally-oriented than men, suggesting that they may prefer to make decisions with others (Eagly, 1983). As population age continues to increase dramatically, it is imperative to understand how decision making may differ across the life span and how key individual difference characteristics may interact to influence these decisions. Participants included members of RAND's American Life Panel (ALP), a national sample of adults in the US. Older age was associated with increased preference to work alone as well as decreased perceived ability to make decisions as one has gotten older and as compared to same-aged peers. Findings also indicated a significant indirect effect of perceived ability to make decisions as compared to same-aged peers on the association between age and preference to make decisions alone and with others. Although this study does not directly examine decisionmaking preferences in the context of decisions themselves, the current study adds to the literature by examining social aspects of decision making, which is typically an understudied area of the literature. 
Table of Contents

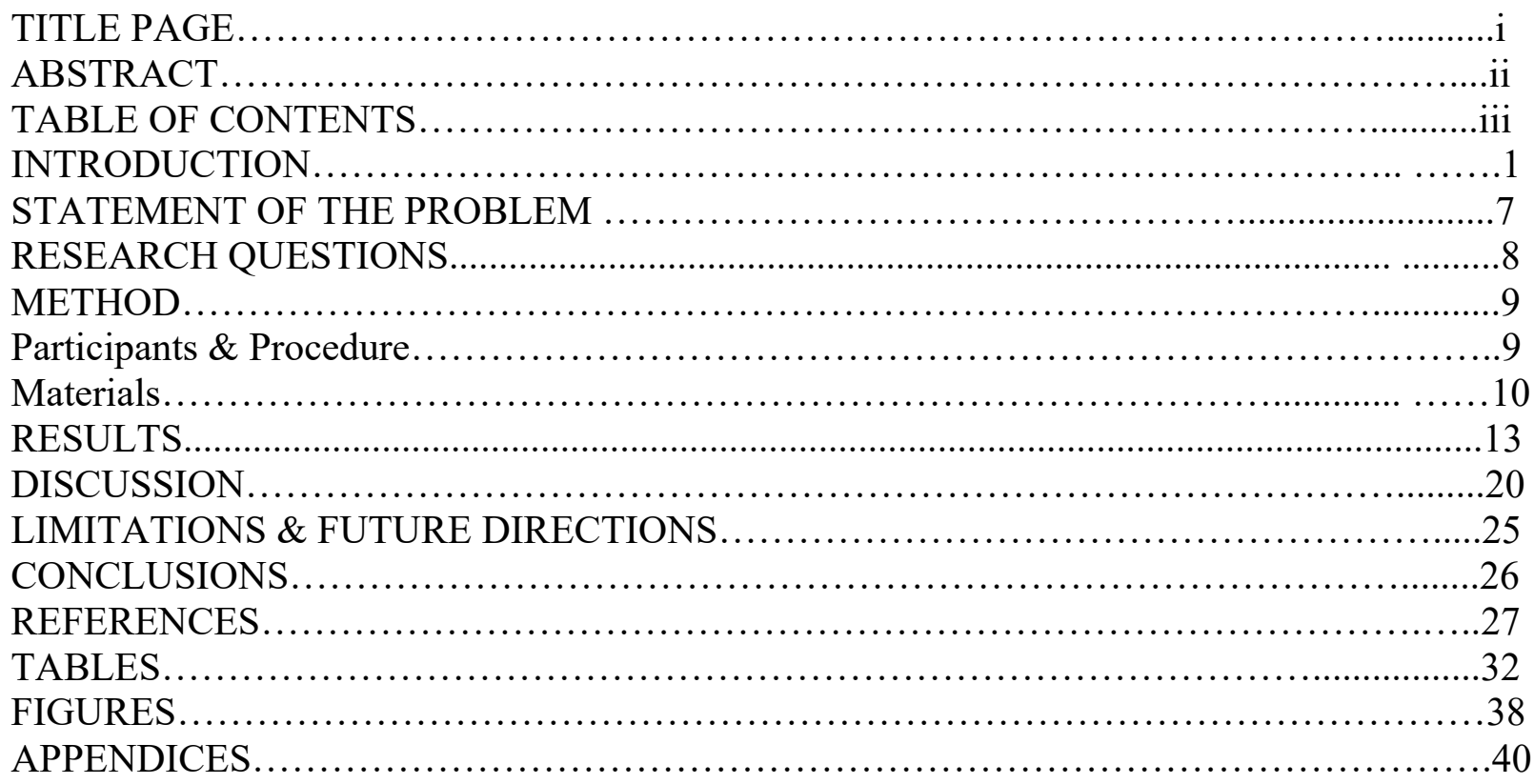


Individual differences in social decision-making preferences

People make decisions large and small every day. These decisions occur in a social context such that people make decisions with others and on behalf of others. Most research to date has focused primarily on the individual decision maker and has not looked at social aspects of decision making. Some research has looked at age differences in preferences for making decisions alone or with others (e.g., Delaney, Strough, Parker, \& Bruine de Bruin, 2015), but findings have been mixed. Understanding the role age plays in decision making preferences is of particular importance as population age increases and there are more aging decision makers than ever before (Oeppen \& Vaupel, 2002). Decision making preferences may also vary based on gender. Women are often theorized to be more interpersonally-oriented than men (Eagly, 1983). Age and gender may be related to individual difference characteristics such as perceived ability to make decisions and beliefs about aging that could be associated with decision-making preferences.

\section{Age and preferences for making decisions alone and with others}

Only a handful of studies assess decision-making preferences. Thornton and Dumke (2005) suggest in their meta-analysis that decision making and problem solving (particularly everyday problem solving) are similar. As such, research from both literatures is reviewed in the following sections. Although there is some inconsistency in the literature, research suggests that when participants are thinking about domain-general or overall preferences for solving everyday problems, older adults prefer to work alone over working with other people. When tasks are domain-specific (for example, in the area of finance or health), however, gender and perceived ability are important for understanding preferences for working alone versus with others (Strough, Cheng, \& Swenson, 2002). 
In contrast to research suggesting that older adults prefer to solve everyday problems alone, research has indicated that older adults are more likely relative to younger adults to report that they prefer to delegate decisions to others (Finucane et al., 2002). Collaborative decision making may become more common in later adulthood, especially if people use a partner for cognitive and interpersonal support (Berg, Schindler, Smith, Skinner, \& Beveridge, 2011). On the other hand, but consistent with domain-general everyday problem solving preferences, one study's findings suggested that older age was associated with being more likely to be classified as having an independent/self-controlled decision making style, indicating that older age was associated with self-reports of making decisions alone (Delaney, et al., 2015).

In terms of methodology, most research directly related to decision making preferences relies on self-report information. Additionally, the surveys Delaney and her colleagues used asked about how they made 'important decisions;' most other research does not make the designation of 'important,' but rather asks about decisions more generally.

\section{Functions of collaboration}

Studies that examine cognitive decline more generally point to the idea of older adults preferring to work with others for compensation or optimization reasons (e.g., Dixon \& Gould, 1998). Although research has not directly assessed preferences for working with others in decision making in the context of cognitive decline, it is likely that this phenomenon exists in that specific case as well. One major theory that may be appropriate here is the theory of selective optimization with compensation (Baltes \& Baltes, 1990); this a model of successful aging that focuses on the processes of maximizing gains and minimizing losses in response to everyday life (Baltes \& Baltes, 1990). Compensation refers to the idea that a limitation or loss can generate different forms of mastery; for example, one can ask advice of others or delegate 
decision making to others that are more skilled to compensate for their perceived declines (Baltes, Lindenberger, \& Staudinger, 2006). Optimization, when considering older adults, refers to the maximization of gains and enhancing strengths (Baltes et al., 2006); for example, older adults who may perceive themselves as the same or better decision makers with age may still elicit others' in their decision making to optimize their existing strengths.

Research on everyday problem solving indicates older adults prefer to work with others to solve everyday problems when they perceive deficits in their functioning (Strough, et al., 2002), suggesting that preferences may reflect compensatory processes. Prior research based on the dataset to be used in the current research indicated that older age was associated with perceiving that one's decision-making has worsened over time (Strough et al., 2016). ${ }^{1}$ Research on aging and problem solving has mainly focused on the advantages of collaboration with others from the perspective of compensation (Meegan \& Berg, 2002). Other research suggests that older adults may use others to optimize their decision making, such as when people use their spouse as a memory 'tool' (Wegner, Erber, \& Raymond, 1991; Andersson \& Ronnberg, 1996). Thus, preferences for working with others to make decisions could serve either a compensatory or optimizing function.

\section{Gender and preferences for making decisions alone or with others}

Research suggests that women seem to be more attuned to social and interpersonal issues in the context of everyday problem solving (Strough, Berg, \& Sansone, 1996). Gender differences in domain-specific problem-solving preferences were consistent with genderstereotypes; people preferred to collaborate in domains that, stereotypically speaking, were domains of competence for the other gender (Strough, et al., 2002). Relatedly, partners may

\footnotetext{
${ }^{1}$ In RAND's American Life Panel (https://alpdata.rand.org), this data for Survey 1 can be found in MS226.
} 
delegate and divide responsibility for everyday tasks that allows for the development of different expertise (Meegan \& Berg, 2002), which often falls upon gender-stereotyped lines. However, when the problem domain was not specified, both men and women reported that they preferred to solve everyday problems alone over working with others (Strough, et al., 2002). In contrast, when Delaney and colleagues (2015) examined decision-making profiles, they found that women were more likely to fall into a so-called 'dependent' decision-making profile, because they were more likely than men to report seeking advice or support from others when making decisions.

In terms of general preferences to make decisions with someone else or alone, because of social roles that contribute to gender differences, women are theorized to be more interpersonally-oriented than men, suggesting that they may prefer to make decisions with others (Eagly, 1983). Gender typicality (feeling that one is a typical member of their gender group) and gender identification (a sense of belonging to a larger gender group) become more salient with age, potentially due to involvement in gendered recreational and educational activities (Lemaster, Delaney, \& Strough, 2017). Taken together, this research suggests that there may be an interaction of age and gender on preferences wherein gender differences for working with others may become more pronounced with age.

\section{Individual characteristics and preferences for making decisions alone and with others}

Other key individual difference characteristics in addition to age and gender may influence decision-making preferences. For example, beliefs about aging and decision making could help reveal whether preferences for working with others to make decisions serves a compensatory or optimizing function. Differences in beliefs about oneself through the aging process as well as comparison to same-age peers are also important to consider. 
Beliefs about aging and decision making. Research indicates that there are declines in skills that underlie decision making, such as working memory, episodic memory, and fluid intelligence; on the other hand, there are other skills related to decision making that are maintained or even improved with age, such as dispositional and anticipated affect, age-related life experience, and crystallized intelligence (see Strough, Parker, \& Bruine de Bruin, 2015 for a review). The extent to which individuals focus on gains and losses of such skills may be reflected in their general beliefs about aging and decision making. For example, some people may focus on gains and hold a belief that decision making improves with age and that generally, people become "older and wiser." Alternatively, many Western societies tend to hold negative views of aging and this may be reflected in believing that aging is associated with worse decision making (Lockenhoff, et al., 2009).

Research has not investigated beliefs about aging and decision making, nor have links with preferences for making decisions alone or with others been examined. However, research has suggested that views about aging have greater impact in domains that are typically associated with stronger negative stereotypes of aging (like health, for example; Hess, et al., 2017). Across cultures, older adults tend to have greater psychological concerns about aging and more concern about domain-specific losses than their younger counterparts (Yun \& Lachman, 2006); both men and women tend to hold this view to similar degrees (Wu, Goins, Laditka, Ignatenko, \& Goedereis, 2009). If making decisions with others serves a compensatory function, those who think that aging leads to decreased decision-making ability may prefer to work with others to make decisions to compensate for age-related declines.

\section{Temporal comparisons of decision-making ability}


In addition to general beliefs about aging and decision making, older adults' temporal comparisons or beliefs about their own abilities compared to how able they felt when they were younger, may be important for understanding their decision-making preferences. If individuals believe that people experience cognitive decline in older age, they may view themselves as less skilled in their own personal decision making as they age. Alternatively, individuals may believe that aging is associated with worse decision making but that they are an 'exception to the rule;' more research is needed to determine which is the case. Other research with the data on which the current project is based showed that people perceived their ability to make decisions had declined with age (Strough et al., 2016). If greater preferences for working with others reflect a compensatory process, older adults may be more likely to prefer making decisions with others when they view themselves as less able than when they were younger.

\section{Social comparisons of decision-making ability}

In addition to comparing how their own decision-making ability has changed over time, people may also make social comparisons and contrast their own abilities to those of others of the same age (see Blanchard-Fields, Chen, \& Norris, 1997; Strough et al., 2002). A review of decision making in older adults indicated that older adults rate their own decision-making competence as worse than younger adults, even though not all facets of decision making decline with age (Strough, Bruine de Bruin, \& Peters, 2015). With increased age, adults perceived their decision-making competence as worse compared to other people of any age (Bruine de Bruin, Parker, \& Fischhoff, 2010). Older adults tend to rate their own general decision-making competence as lower than younger adults, and also rate their decision-making competence in specific domains (namely, healthcare and daily life decisions) as worse than younger and middleaged adults (Bruine de Bruin et al., 2010; Woodward \& Wallston, 1987). Research using part of 
this dataset that examined perceived ability to make decisions compared to same age peers and found that older age was associated with viewing one's decision making abilities as worse than others the same age (Strough et al., 2016). Within the everyday problem-solving literature, older adults who perceived that their problem solving abilities were poorer than their same-aged peers were more likely to prefer working with others (Strough, et al., 2002). If this finding holds for decision-making preferences, we would expect that older adults who perceived themselves as less able decision makers than their peers would prefer to work with others to make decisions.

\section{Statement of the Problem}

As population age continues to increase dramatically, it is imperative to understand how decision making may differ across the life span and how key individual difference characteristics may interact to influence these decisions. Women seem to be more attuned to social and interpersonal issues in the context of problem solving (Strough, et al., 1996). Both women and men prefer to solve everyday problems alone when the domain of the problem is not specified (Strough, et al., 2002), but other research found that women are more likely to endorse an interpersonally-oriented decision-making style (Delaney et al., 2015). Age may be related to decision-making preferences to work with others if older adults draw on others to compensate for perceived declines in their abilities. The present study will address limitations of the existing literature by investigating how individual differences characteristics, including perceived ability to make decisions in the context of both social and temporal comparisons, and beliefs about aging, are uniquely associated with gender and age differences in decision-making preferences.

\section{Current Study}

The overall goal of the current study is to examine age, gender, and other individual difference characteristics related to preferences to make decisions alone and with others. 
Research question 1. Are there age and gender differences in preferences to make decisions alone and with others?

Hypothesis 1a. Drawing from research that suggests that older adults prefer to delegate decision making to others, (Finucane et al., 2002), I expect that older age will be associated with the preference to make decisions with others.

Hypothesis 1b. Drawing from research which suggests that women seem to be more attuned to social and interpersonal issues in the context of everyday problem solving than men (Strough, et al., 1996), I expect that women will be more likely to prefer making decisions with others than men.

Research question 2. Are there age and gender differences in perceived ability to make decisions?

Hypothesis 2a. Based on prior research with the larger dataset (Strough et al., 2016) from which the data for the current study will be drawn, I expect to replicate the finding that older age will be associated with perceptions that one's decision-making abilities will have gotten worse over time.

Hypothesis 2. Because men and women tend to hold similar views about cognitive decline (Wu, et al., 2009), I expect that there will not be gender differences in perceived ability to make decisions.

Research question 3. Are there age and gender differences in beliefs about aging and decision making?

Hypothesis 3a. Based on research suggesting that older adults may have negative views about aging in certain domains (Hess, et al., 2017), I hypothesize that older age will be associated with negative beliefs about aging and decision making. 
Hypothesis 3b. Because men and women tend to hold similar views about cognitive decline (Wu, et al., 2009), I expect that there will not be gender differences in beliefs about aging and decision making.

Research Question 4. Are any of these individual difference characteristics (temporal comparisons of perceived ability, social comparisons of perceived ability, beliefs about aging and decision making, age, or gender) related to decision-making preferences?

Hypothesis 4. Drawing from prior research (Strough et al., 2002), I expect that greater preference to work with others will be associated with worse perceived ability to make decisions compared to one's younger self (temporal) as well as compared to same-aged peers (social). Further, I expect that greater preference to work with others will be associated with decreased beliefs about aging and decision making.

Research question 5. Do any of these individual difference characteristics (beliefs about aging and decision making, temporal comparisons of perceived ability, or social comparisons of perceived ability) mediate age differences in decision making preferences?

Hypothesis 5. Since I anticipate that older adults' preference to work with others will reflect compensation rather than optimization, I hypothesize that age differences in decisionmaking preference will be mediated by temporal and social comparisons of perceived ability and beliefs about aging and decision making.

\section{Method}

\section{Participants}

For this project, I conducted secondary analyses of data collected with a national adult life-span sample. Participants included 1,075 members of RAND’s American Life Panel (ALP), a national sample of adults in the US who regularly receive invitations to complete internet 
surveys (https://mmicdata.rand.org/alp/). Data used for this project was collected in the months of December 2011 and January 2012. ${ }^{2}$ Participants received approximately $\$ 20$ per 30 minutes of survey completion time. The sample consisted of women (56.2\%) and men (43.8\%) who ranged from 18 to 93 years of age $\left(\mathrm{M}_{\mathrm{age}}=53.49, \mathrm{SD}_{\mathrm{age}}=14.19\right)$. The majority of participants were White $(84.9 \%)$ and married or living with a partner (61.3\%). Other demographic information about the sample including level of education can be found in Table 1. Of note, the majority of this sample was at least partially college educated.

\section{Procedure}

The survey was sent to 1,353 panelists, 1,075 who responded (for a $79.5 \%$ response rate). Data were collected online using self-report measures. Some of the measures were adapted from prior research (e.g., temporal comparisons of perceived ability; see Strough, et al., 2002). Others, including the measure about beliefs about aging and decision making, were created by Andrew Parker. All measures used in this study can be found in Appendices A-D, and F.

\section{Measures}

Demographics. Participants reported their age, as well as their gender, marital status, family income, ethnicity, and highest education attained. These data are collected quarterly as part of the ALP. Age was treated as a continuous variable in all analyses.

Self-rated health. In addition to demographic information, participants responded to four questions related to their perceived health status that were summed to create a measure of perceived health from the Multilevel Assessment Instrument (e.g., "How would you rate your overall health at the present time?"; Lawton, Moss, Fulcomer, \& Kleban, 1982). A Likert scale

\footnotetext{
${ }^{2}$ Participants for this study were recruited for ms232. Information on perceived ability was collected in ms 226 . Both surveys were in the field at the same time. ms226 was available from December 2011 to March 2013; ms232 was available from December 2011 to January 2012.
} 
from 1 ("better/not at all") to 3 ("not as good/a great deal") was used for three of the items; the other item used a Likert scale from 1 (“excellent”) to 4 (“poor"). All items were worded such that higher scores indicated worse health $(\alpha=.757)$. This measure was used in all analyses as a control variable because prior research (Strough et al., 2016) showed it was associated with perceived ability.

Decision-making preferences to work with others. Preferences for working with others to make decisions were indexed by three items, adapted from a measure used a study by in Strough and colleagues (2002) assessing problem solving preferences (e.g., "When making decisions in your everyday life, do you prefer to work with other people?"). A Likert scale from 1 ("do not prefer/like") to 5 ("very much prefer/like") was used. Ratings on each item were summed to create a 'prefer to make decisions with others' score $(\alpha=.78)$. Higher scores indicated greater preference to make decisions with others.

Decision making preferences to work alone. Preferences for working alone to make decisions were indexed by three items, adapted from a measure used in a study by Strough and colleagues (2002) assessing problem-solving preferences (e.g., "When making decisions in your everyday life, do you prefer to work alone?"). A Likert scale from 1 (“do not prefer/like") to 5 ("very much prefer/like") was used. Ratings on each item were summed to create a "prefer to make decisions alone' score $(\alpha=.81)$. Higher scores indicated greater preference to make decisions alone.

Beliefs about aging and decision making. Beliefs about aging and decision making were assessed with nine items (e.g., "Experience comes with age," and "People with more experience make more rational decisions,") created for this study. A Likert scale from 1 ("strongly disagree") to 5 ("strongly agree") was used. Because this questionnaire was created 
for the purposes of this study, an exploratory factor analysis was conducted on this measure; for information on that analysis, see Appendix E. The internal consistency of the scale with all nine items was acceptable $(\alpha=.67)$, but was improved by the deletion of 4 items based on the outcome of an Exploratory Factor Analysis; thus, 5 items were used to create the scores used in the analysis ( $\alpha=.78$; see Appendix E for more information). Higher scores indicated more positive beliefs about aging and decision making. The final version of this measure used in primary analyses can be found in Appendix F.

Perceived changes in decision making ability with age. Three items adapted from a study conducted by Strough and colleagues (2002) assessed perceptions of how one's decision making abilities had changed with age (e.g., "As I have gotten older, my ability to make decisions is:"). Participants completed statements by indicating whether they believed their abilities were " 1 = better," " 2 = the same," or " 3 = not as good". Responses were recoded such that higher scores indicated better perceived ability to make decisions as one has gotten older. The internal consistency of the scale was $\operatorname{good}(\alpha=.84){ }^{3}$

Perceived decision making ability compared to age peers. Three items adapted from a study conducted by Strough and colleagues (2002) assessed perceived decision making abilities in relation to peers (e.g., "Compared with most people your age, would you say your ability to make decisions is:"). Participants completed statements by indicating whether they believed their abilities were " $1=$ better," " $2=$ the same," or " 3 = not as good". Responses were recoded such that higher scores indicated better perceived ability to make decisions as compared to same-aged peers. The internal consistency of the scale was good $(\alpha=.82){ }^{3}$

\footnotetext{
${ }^{3}$ Results based on the relation between these items and future time perspective were reported in Strough et al., 2016. Strough et al. (2016) examined relationships between this and other variables and future time perspective. Their findings based on a regression analysis indicated that perceiving improvements in one's decision making ability with age, and better decision making ability compared with age peers were both associated with focusing more on future
} 


\section{Results}

\section{Data Cleaning}

Before any analyses were conducted, data were cleaned and checked for assumptions.

First, the data were inspected for issues with missingness and univariate and multivariate issues. Because the amount of missingness was low $(<5 \%)$ and missingness that did exist was determined to be missing completely at random, Expectation-Maximization (EM) was implemented to impute missing data. To examine multivariate issues, a regression was conducted with all variables entered into the analysis with identification number as the dependent variable. Inspection of the Mahalanobis distance resulting from this regression suggests that there were no multivariate issues (e.g., tolerance, VIF).

There were no major outliers, but several variables were negatively skewed, including preferences to make decisions alone, perceived ability to make decisions as one has gotten older, and perceived ability to make decisions as compared to same-age peers; no variables were kurtotic. To address the issue of skew, the variables affected were reflected and a square root transformation was applied to preferences to make decisions alone and perceived ability to make decisions as compared to same-aged peers; a log base 10 transformation was applied to perceived ability to make decisions as one has gotten older. The square root transformations normalized the affected variables, and the log base 10 transformation improved the skew of that affected variable. All analyses using the affected variables were conducted with both the original variables and the skew-adjusted variables. Most findings were unchanged when using the 
original variables or the skew-adjusted variables. The values from the analyses with the untransformed values are reported for ease of interpretation. ${ }^{4}$

Research Question 1: Are there age and gender differences in decision-making preferences to work alone or with others?

A mixed model analysis of variance (ANOVA) was used to examine whether gender and age were related to preferences to work with others or work alone when making decisions. Gender (male, female) and age were the between-subjects variables, and decision-making preferences (alone, with others) was the within-subjects variable. Age was treated as a continuous variable in this and all subsequent analyses. The interaction of age and decisionmaking preference was significant, $F(1,1070)=20.603, p<.001$, partial $\eta^{2}=.019$. Older age was associated with greater preferences to make decisions alone $(r=.09)$ and lesser preferences to make decisions with others $(\mathrm{r}=-.12$; see Table 2 for all correlations among key study variables). Additionally, the difference in correlations was tested using Fisher's R to Z transformation (Weiss, 2011), and the correlations were significantly different, $\mathrm{z}=4.83, p<$ .001 .The main effect of preferences and the interaction effects of gender and preferences as well as the interaction of gender, age, and preferences were nonsignificant. ${ }^{5}$

Research Question 2: Are there age and gender differences in perceived ability to make decisions?

To examine whether there were age and gender differences in perceived ability to make decisions, two multiple regression analyses were conducted. For each analysis, perceived health

\footnotetext{
${ }^{4}$ A few additional findings emerged when using the adjusted variables and are described where applicable.

${ }^{5}$ When using the skew-adjusted variables, an additional interaction of decision-making preference, age, and gender was significant, $F(1,1070)=5.497, p<.05$, partial $\eta^{2}=005$. This interaction indicates that the overall pattern of the association between older age and preference to make decisions alone is more pronounced for women than for men.
} 
was entered as a covariate on the first step; age, and gender were entered on the second step, and the interaction of age and gender was entered on the third step.

Perceived ability to make decisions as one has gotten older

The outcome variable for the first analysis was perceived ability to make decisions as one has gotten older. The overall model with perceived ability to make decisions as one has gotten older (perceived temporal ability) was significant, $F(4,1070)=39.50, p<.001, \mathrm{R}^{2}=.129$ (see Table 3). Age uniquely contributed to the variance of the model, $\beta=-.295, p<.01$, such that older age was associated with worse perceived ability to make decisions as one has gotten older. Perceived ability to make decisions as compared to same-aged peers

In this second regression, the outcome variable was perceived ability to make decisions as compared to same-aged peers. The overall model with perceived ability as compared to sameaged peers (perceived social ability) was significant, $F(4,1070)=20.713, p<.001, \mathrm{R}^{2}=.072$ (see Table 3). Age uniquely contributed to the variance of the model, $\beta=-.068, p<.05$, such that older age was associated with worse perceived ability to make decisions as compared to sameaged peers. Gender also uniquely contributed to the variance of the model, $\beta=-.116, p<.001$, such that females' $(M=2.41)$ perceived abilities in relation to same-aged peers were lower than males' $(\mathrm{M}=2.51)$ perceived abilities. $^{6}$

Research Question 3: Are there age and gender differences in beliefs about aging and decision making?

To examine whether there were age and gender differences in perceived benefits of aging for decision making, a multiple regression analysis was conducted. Perceived health was controlled on the first step; age, and gender were entered on the second step, and the interaction

\footnotetext{
${ }^{6}$ When using the skew-adjusted variables, all findings were unchanged.
} 
of age and gender was entered on the third step. The overall model was not significant, $F$ (4, $1070)=.750, p=.56 .^{7}$

Research Question 4: Are any of these individual difference characteristics (temporal comparisons of perceived ability, social comparisons of perceived ability, perceptions about aging and decision making, age, or gender) related to decision-making preferences?

To examine whether greater preferences for making decisions alone or with others were related to age, gender, perceived ability to make decisions as one has gotten older, perceived ability to make decisions as compared to same-aged peers, and perceived benefits of aging in decision making, two multiple regression analyses were conducted. The first analysis used preferences to make decisions alone as the dependent variable, and the second used preferences to make decisions with others as the dependent variable. For each analysis, perceived health was controlled for on the first step and all other variables were entered simultaneously on the second step.

\section{Preferences to make decisions alone}

The overall model with preferences to make decisions alone was significant, $F(6,1068)=$ 4.880, $p<.001, \mathrm{R}^{2}=.027$ (see Table 4). Age uniquely contributed to the variance of the model, such that older age was associated with increased preference to make decisions alone. Perceived ability to make decisions as compared to same-aged peers contributed to the model; greater perceived ability to make decisions as compared to same-aged peers was associated with increased preference to make decisions alone. ${ }^{8}$

Preferences to make decisions with others

\footnotetext{
${ }^{7}$ When using the skew-adjusted variables, all findings were unchanged.

${ }^{8}$ When using the skew-adjusted variables, all findings were unchanged.
} 
Similarly, the overall model with preferences to make decisions with others as the dependent variable was significant, $F(6,1068)=8.000, p<.001, \mathrm{R}^{2}=.043$ (see Table 4). All five predictors entered into the model uniquely contributed to the variance of the model.

Age uniquely contributed to the variance of the model such that older age was associated with decreased preference to make decisions with others. Gender uniquely contributed to the variance of the model such that women $(M=8.87)$ were less likely than men $(M=9.06)$ to prefer to make decisions with others. Perceiving one's ability to make decisions as one has gotten older as improving was associated with increased preference to make decisions with others. Perceiving one's ability to make decisions as compared to same aged peers as improving was associated with decreased preference to make decisions with others. Increased positive beliefs about the perceived benefits of aging for decision making was associated with increased preference to make decisions with others. $^{9}$

Research Question 5: Do any of these individual difference characteristics (perceptions about aging and decision making, temporal comparisons of perceived ability, or social comparisons of perceived ability) mediate age differences in decision-making preferences?

Two parallel mediated multiple linear regressions were conducted using Hayes's PROCESS macro (Hayes, 2018). For both analyses, age was the predictor variable, and either preferences to make decisions alone or preferences to make decisions with others as the outcome variable. As with earlier analyses, perceived health was entered as a covariate. Gender was also entered as a covariate in these analyses. Variables that were identified in prior analyses as significant correlates with preferences to make decisions alone and with others, respectively,

\footnotetext{
${ }^{9}$ When using the skew-adjusted variables, all findings were unchanged.
} 
were tested as mediators. For example, for preferences to make decisions alone, only perceived ability to make decisions as compared to same-aged peers was tested a mediating variable.

\section{Preferences to make decisions alone}

In the first analysis with preferences to make decisions alone as the outcome variable, older age was associated with worse perceived ability to make decisions compared to same-aged peers $(B=-.0024, p=.0219)$. After controlling for age, gender and perceived health, better perceived ability to make decisions as compared to same-aged peers was associated with greater preferences to make decisions alone $(B=.6026, p=.0003$; see Figure 1$)$. The total effect of age on preferences to make decisions alone was significant $(B=.0189, p=.0007)$, but was smaller than the direct effect $(B=.0203, p=.0003)$ after taking the indirect path for the mediator into account. This indicated that there was a suppressor effect where controlling for the path through perceived social ability amplified the association between age and greater preferences to make decisions alone $(B=-.0014 ; 95 \%$ CI $[-.0032,-.0001]$; see Table 5). Older age was associated with increased preference to make decisions alone despite older adults' worse perceptions of their ability to make decisions compared to same-aged peers. ${ }^{10}$

\section{Preferences to make decisions with others}

In the second analysis with preferences to make decisions with others as the outcome variable, older age was associated with reporting worse perceived ability to make decisions as one had gotten older $(B=-.0110, p=.0000$; see Figure 2$)$, worse perceived ability to make decisions as compared to same-aged peers $(B=-.0024, p=.0219)$, and was not significantly associated with perceived benefits of aging in decision making $(p=.2758)$. After controlling for age, gender and perceived health, worse perceived ability to make decisions as one has gotten

\footnotetext{
${ }^{10}$ When using the skew-adjusted variables, all findings were unchanged.
} 
older $(B=.4768, p=.0058)$ and lower perceived benefits of aging for decision making $(B=$ $.0786, p=.0008)$ were associated with decreased preference to make decisions with others; additionally, worse perceived ability to make decisions as compared to same-aged peers were associated with greater preference to make decisions with others $(B=-.4800, \mathrm{p}=.0074)$. The total effect of age on preferences to make decisions alone was significant $(B=-.0261, \mathrm{p}=.0001)$, but was smaller than the direct effect $(B=-.0226, \mathrm{p}=.0000)$ after taking the total indirect paths for perceived ability to make decisions as one has gotten older, perceived ability to make decisions as compared to same-aged peers, and perceived benefits of aging in decision making into account. Although the total of the indirect paths through the three mediators was not significant $(B=-.0035 ; 95 \%$ CI $[-.0074, .0004])$, one of the three individual indirect effects were significant (see Table 5). The indirect effect of perceived ability to make decisions as one had gotten older was significant, $B=-.0052$, CI [-.0092, -.0015]. This finding suggests that older individuals, who perceive their ability to make decisions as getting worse as they have gotten older, were less likely to want to work with other people. ${ }^{11}$

\section{Discussion}

People of all ages make decisions every day, and much of the time these decisions are made with the input of others. Although this study does not directly examine decision-making preferences in the context of decisions themselves, the current study adds to the literature by examining social aspects of decision making, which is typically an understudied area of the literature. Several of the proposed hypothesis were supported, as well as several other significant findings that were not hypothesized. As such, findings from the current study meaningfully contribute to the literature on individual differences in decision making.

\footnotetext{
${ }^{11}$ When using the skew-adjusted variables, all findings were unchanged.
} 


\section{Age and Gender Differences in Preferences to Work Alone and with Others}

Hypothesis 1a, that older age will be associated with the preference to make decisions with others, was not supported. On the contrary, older age was associated with greater preference to make decisions alone and less preference to work with others in the current study. The research in this area is mixed, but research had suggested that older adults prefer to work alone to solve their everyday problems (Strough et al., 2002) and make decisions (Delaney et al., 2015). However, Finucane and colleagues' (2002) research suggested that older adults were more likely to delegate decisions to others. One explanation for the inconsistency could reflect that preferences vary based on the identity of the 'other' person the participant has in mind when responding to questions about preferences for making decisions with others. For example, collaborating with a physician or financial advisor may be differently preferred than making decision with a close family member, depending on the circumstances. Inconsistency in preferences may also reflect whether domain-general or domain-specific preferences are assessed. In the current study, domain general preferences for making decisions alone were found, similar to everyday problem solving research. The outcome of the current study might be further evidence of the similarity between everyday problem solving and decision making (Thornton \& Dumke, 2005). More research is necessary that employs measures beyond selfreport (like the problems used in Finucane et al., 2002) to elucidate if these different methods of measurement are at the root of inconsistent findings in this area.

Hypothesis $1 \mathrm{~b}$, that women will be more likely to prefer making decisions with others than men, was also not supported; there was no association between gender and decision-making preference. Although the literature on gender and decision making is relatively limited, research has demonstrated that women are more attuned to social and interpersonal issues in everyday 
problem solving (Strough et al., 1996). Additionally, Delaney and colleagues (2015) also indicated that women are more likely to be characterized into a dependent decision-making profile (i.e., seeking advice of others). While there is some research on gender differences in domain-specific problem solving, the limited research that has examined gender and domaingeneral problem solving is in line with our findings, suggesting that both men and women prefer to solve everyday problems alone (Strough et al., 2002).

It is important to note that preferences to make decisions alone and preferences to make decisions with others are significantly correlated with one another, $r=-.54, p<.001$. It would likely be expected that these constructs would be more strongly correlated than that because they are two directly opposing constructs on the surface. Although it is not entirely clear why this is the case, one potential explanation is that both measures of decision making preference are domain general, rather than tailored to specific domains, such as health or finance.

\section{Age and Gender Differences in Perceived Ability to Make Decisions as One has Gotten Older and to Make Decisions Compared to Same-Aged Peers}

Hypothesis 2a, that older age will be associated with perceptions that one's decisionmaking abilities will have gotten worse as one has gotten older, was confirmed, replicating earlier work with the larger dataset used in this study (Strough et al., 2016). An additional finding emerged indicating that older age was also associated with decreased perceived ability to make decisions as compared to same-aged peers, which also replicated earlier work with the larger dataset used in this study (Strough et al., 2016). Although research has not directly looked at one's perceptions of their own abilities as they've changed with age, this result is in line with research that has suggested that older adults perceive their decision-making competence to be 
worse than younger adults (Strough et al., 2015), as well as worse as compared to people of any age (Bruine de Bruin et al., 2010).

Hypothesis $2 b$, that gender differences would not be present in perceived ability to make decisions, was partially supported. Gender differences did not emerge in individuals' perceived ability to make decisions as they've gotten older; but they did emerge in individuals' perceived ability to make decisions as compared to same-aged peers. Specifically, women were more likely than men to have lower perceived ability to make decisions compared to same-aged peers. Although the literature has not examined gender differences in perceived ability to make decisions to date, it makes conceptual sense that women report lower perceived ability to make decisions compared to same-aged peers; women, on average, participate in social comparison to a greater degree than men (Guimond et al., 2007), especially within their own gender.

\section{Age and Gender Differences in Benefits of Aging in Decision Making}

Hypothesis $3 \mathrm{a}$, that older age will be associated with negative beliefs about aging and decision making, was not supported; there was no association between age and benefits of aging in decision making. Hypothesis $3 \mathrm{~b}$, that gender differences in beliefs about aging and decision making will not exist, was supported; there was no association between gender and benefits of aging in decision making. The lack of findings in regards to this measure and the lack of prior research in this area may indicate that more work needs to be done in validating this measure and examining this construct in relation to decision making more generally.

\section{Effects of All Key Variables on Preferences to Work Alone and with Others}

Hypothesis 4, that greater preference to work with others will be associated with decreased temporal and social comparisons of perceived ability, was partially supported. In contrast to the first part of the hypothesis, greater preference to make decisions with others was 
associated with greater perceived ability to make decisions as one has gotten older. This may suggest that older adults perceive a sense of wisdom that they want to impart onto others. Confirming the second part of the hypothesis, greater preference to make decisions with others was associated with decreased perceived ability to make decisions as compared to same-aged peers. This likely reflect that those who prefer working with others may want to compensate for their perceived shortcomings in decision making (Strough et al., 2002).

An additional hypothesis, that greater preference to work with others will be associated with decreased beliefs about aging and decision making, was not supported. On the contrary, greater preference to work with others was associated with increased positive beliefs about aging and decision making. This finding indicates that participants perceive that aging offers advantages in decision making. This would support the idea proposed earlier that individuals who prefer to work with others to make decisions may do so optimize their decision making and that of others (Baltes et al., 2006). As the literature has not examined individuals' positive beliefs about aging and decision making in this way, this is a novel contribution to the literature.

Several additional findings emerged from this analysis. Firstly, women were less likely than men to prefer to make decisions with others; this was an unexpected finding, as research has indicated that women are more interpersonally oriented, on average, than men in the context of everyday problem solving (Strough et al., 1996) and in the context of decision making (Delaney et al., 2015). Additionally, older age was associated with decreased preference to make decisions with others; older age was also associated with increased preference to make decisions alone. Although the literature is mixed, this is in line with prior research suggesting that older adults prefer to work alone when solving everyday problems (Strough et al., 2002) and that older adults are more likely to be classified as having an independent/self-controlled decision-making style 
(Delaney et al., 2015). Finally, individuals' greater perceived ability to make decisions as compared to their same-aged peers was associated with increased preference to make decisions alone. This may suggest that individuals who perceive themselves as similarly competent or more competent than their peers may prefer to work alone because these individuals do not consider making decisions with others because they perceive themselves as competent decision makers

\section{Indirect Effects on Preferences to Work Alone and with Others}

Hypothesis 5, that age differences in decision-making preference will be mediated by temporal and social comparisons of perceived ability and beliefs about aging and decision making, was partially supported. First, although a parallel mediation where all three mediators were entered simultaneously with preferences to make decisions alone was proposed, different analyses were conducted. Due to the outcome of Research Question 4, only one mediating variable was used because it was the only variable to have a significant relationship with the outcome: perceived ability to make decisions as compared to same-aged peers. This analysis did yield significant results. Specifically, there was a suppressor effect here, where controlling for the path through perceived social ability amplified the association between age and preferences to make decisions alone. Older age was associated with increased preference to make decisions alone despite older adults' worse perceptions of their ability to make decisions compared to same-aged peers. The reason for this is unclear; perhaps older adults may not want to display their perceived decline in ability to others.

The indirect effects hypothesized were partially supported. One of the three individual mediators yielded significant indirect effect in this analysis. The first indirect effect that emerged was perceived ability to make decisions as one has gotten older. Specifically, older individuals, 
who perceive their ability to make decisions as getting worse as they have gotten older, were less likely to want to work with other people. More research is needed in this area to elucidate the specific mechanisms behind this finding. Additionally, there was an indirect effect of perceived ability to make decisions as compared to same-aged peers. Specifically, older individuals, who perceive their ability to make decisions as worse compared to same-aged peers, were more likely to want to work with other people. In line with earlier research in this area (Baltes et al., 2006), this finding suggests that older individuals may be compensating for perceived losses in ability to make decisions by eliciting help from other people in their decision-making process.

\section{Limitations, Future Directions and Conclusions}

Because the cross-sectional nature of the current study, the data cannot address causality or cohort effects (Lindenberger, van Oertzen, Ghisletta, \& Hertzog, 2011; Schaie, 2012). The correlational methods of the current study prohibit the ability to draw conclusions about perceptions of age-related improvements or declines in ability over time. Future research should be longitudinal in nature to discern directionality of effects. Future research should also assess actual change in ability to make decisions over time, rather than merely perceptions. Another future direction of research in this area could examine how preferences to make decisions with others or alone may differ based on degree of cognitive decline. For example, we may see domain-general preferences to make decisions with others in older adults who are aware that they are experiencing cognitive decline. Additionally, the measures used herein are entirely selfreport; future research should also examine what people actually do when they are making decisions. Another limitation is the use of measures that were not validated prior to the current study. Although this was primarily related to the measure on beliefs about aging and decision making, the other measures are not widely used. Thus, their utility may be limited in scope, 
despite the advantage of their length. Future research should make use of these measures in addition to other similar measures to further establish validity and reliability.

\section{Conclusion}

In conclusion, understanding individual differences in decision making is an important and understudied area of the literature. Individual differences in social components of decision making (e.g., preferences regarding involving others' in the decision-making process, perceptions of decision-making abilities as compared to same-aged peers) is another understudied area of the literature that the current study contributes to. Results suggest that the associations among individual difference characteristics and decision-making preferences are complex and do not present a clear picture of optimization and compensation, indicating that more research should be done in this area to attempt replication and further validate the measures used in the current study. 


\section{References}

Andersson, J., \& Ronnberg, J. (1996). Collaboration and memory: Effects of dyadic retrieval on different memory tasks. Applied Cognitive Psychology, 10, 171-181.

Baltes, P., \& Baltes M. (1990). Psychological perspectives on successful aging: The model of selective optimization with compensation. In P. Baltes \& M. Baltes (Eds.), Successful aging: Perspectives from the behavioral sciences (pp. 1-34). Cambridge, UK: Cambridge University Press. doi:10.1017/CBO9780511665684.003

Baltes, P.B., Lindenberger, U., \& Staudinger, U.M. (2006). Life-span theory in developmental psychology. In W. Damon \& R.M. Lerner (Series Eds) \& R.M. Lerner (Volume Ed.). Handbook of child psychology: Vol. 1. Theoretical models of human development. $6^{\text {th }}$ ed. (pp. 569-664). New York: Wiley.

Berg, C. A., Schindler, I., Smith, T. W., Skinner, M., \& Beveridge, R. M. (2011). Perceptions of the cognitive compensation and interpersonal enjoyment functions of collaboration among middle-aged and older married couples. Psychology and Aging, 26(1), 167-173. $\underline{\text { http://dx.doi.org/10.1037/a0021124 }}$

Blanchard-Fields, F., Chen, Y., \& Norris, L. (1997). Everyday problem solving across the adult life span: Influence of domain specificity and cognitive appraisal. Psychology and Aging, 12(4), 684-693. http://dx.doi.org/10.1037/0882-7974.12.4.684

Bruine de Bruin, W., Parker, A.M., \& Fischhoff, B. (2010). Explaining adult age differences in decision-making competence. Journal of Behavioral Decision Making, 25, 352-360. doi: $10.1002 / \mathrm{bdm} .712$ 
Delaney, R., Strough, J., Parker, A.M. \& Bruine de Bruin, W. (2016). Variations in decisionmaking profiles by age and gender: A cluster-analytic approach. Pers Individ Dif, 85, 117. doi:10.1016/j.paid.2015.04.034

Dixon, R.A., \& Gould, O.N. (1998). Younger and older adults collaborating on retelling everyday stories. Applied Developmental Science, 2, 160-171.

Eagly, A.H. (1983). Gender and social influence: A social psychological analysis. American Psychologist, 38, 971-981. http://dx.doi.org/10.1037/0003-066X.38.9.971

Finucane, M.L., Slovic, P., Hibbard, J.H., Peters, E., Mertz, C.K., \& MacGregor, D.G. (2002). Aging and decision-making competence: An analysis of comprehension and consistency skills in older versus younger adults considering health-plan options. Journal of Behavioral Decision Making, 15, 141-164. Doi:10.1002/bdm.407

Guimond, S., Branscombe, N. R., Brunot, S., Buunk, A. P., Chatard, A., Désert, M., ... \& Yzerbyt, V. (2007). Culture, gender, and the self: Variations and impact of social comparison processes. Journal of Personality and Social Psychology, 92, 1118-1134. doi:10.1037/0022-3514.92.6.1118

Hayes, A.F. (2018). Introduction to mediation, moderation, and conditional process analysis: A regression-based approach (2nd Edition). New York: Guilford Press.

Hess, T.M., O’Brien, E.L., Voss, P., Kornadt, A.E., Rothermund, K., Fung, H.H., \& Popham, L.E. (2017). Context influences on the relationship between views of aging and subjective age: The moderating role of culture and domain of functioning. Psychology and Aging, 32, 419-431. http://dx.doi.org/10.1037/pag0000181 
Lawton, M.P., Moss, M., Fulcomer, M., \& Kleban, M.H. (1982). A research and service oriented Multilevel Assessment Instrument. Journal of Gerontology, 37, 91-99. https://doi.org/10.1093/geronj/37.1.91

Lemaster, P., Delaney, R., \& Strough, J. (2017). Crossover, degendering, or...? A multidimensional approach to life-span gender development. Sex Roles, 76, 669-681. Doi:10.1007/s11190-015-0563-0

Lindenberger, U., Von Oertzen, T., Ghisletta, P., \& Hertzog, C. (2011). Cross-sectional age variance extraction: What's change got to do with it?. Psychology and Aging, 26, 34-47. doi:10.1037/a0020525

Lockenhoff, C.E., De Fruyt, F., Terracciano, A., McCrae, R.R., De Bolle, M., Costa Jr., P.T., ... Yik, M. (2009). Perceptions of aging across 26 cultures and their culture-level associates. Psychology and Aging, 24, 941-954. Doi:10.1037/a0016901

Meegan, S.P., \& Berg, C.A. (2002). Contexts, functions, forms, and processes of collaborative everyday problem solving in older adulthood. International Journal of Behavioral Development, 26, 6-15. Doi:10.1080/01650250143000283

Oeppen, J., \& Vaupel, J.W.. (2002). Demography. Broken limits to life expectancy. Science, 296, 1029-1031. Doi: 10.1126/science.1069675

Schaie, K. W. (2012). Developmental influences on adult intelligence: The Seattle Longitudinal Study. New York, NY: Oxford University Press.

\section{https://doi.org/10.1093/acprof:oso/9780195156737.003.0006}

Strough, J., Berg, C. A., \& Sansone, C. (1996). Goals for solving everyday problems across the life span: Age and gender differences in the salience of interpersonal 
concerns. Developmental Psychology, 32(6), 1106-1115. http://dx.doi.org/10.1037/0012$\underline{1649.32 .6 .1106}$

Strough, J., Bruine de Bruin, W., Parker, A.M., Lemaster, P., Pichayayothin, N., \& Delaney, R. (2016). Hour glass half-full or half-empty? Future time perspective and preoccupation with negative events across the life span. Psychology and Aging, 31, 558-573. Doi:10.1037/pag0000097

Strough, J., Bruine de Bruin, W., \& Peters, E. (2015). New perspectives for motivating better decisions in older adults. Frontiers in Psychology, 6, 1-10. doi:10.3389/fpsyg.2015.00783

Strough, J., Cheng, S., Swenson, L.M. (2002). Preferences for collaborative and individual everyday problem solving in later adulthood. International Journal of Behavioral Development, 26, 26-35. doi:10.1080/01650250143000337

Strough, J., Parker, A., \& Bruine de Bruin, W. (2015). Understanding Life-Span Developmental Changes in Decision-Making Competence. In Aging and Decision Making: Empirical and Applied Perspectives (pp. 371-392). London, UK: Academic Press.

Thornton, W.J.L., \& Dumke, H.A. (2005). Age differences in everyday problem-solving and decision-making effectiveness: A meta-analytic review. Psychology and Aging, 20, 8599. Doi:10.1037/0882-797.20.1.85

Wegner, D.M., Erber, R., \& Raymond, P. (1991). Transactive memory in close relationships. Journal of Personality and Social Psychology, 61, 923-929

Weiss, B.A. (2011). Fisher's r-to-Z transformation calculator to compare two independent samples [Computer software]. Available from https://blogs.gwu.edu/weissba/teaching/calculators/fishers-z-transformation/. 
Woodward, N. J., \& Wallston, B. S. (1987). Age and health care beliefs: Self-efficacy as a mediator of low desire for control. Psychology and Aging, 2(1), 3-8. http://dx.doi.org/10.1037/0882-7974.2.1.3

Wu, B., Goins, R.T., Laditka, J.N., Ignatenko, V., \& Gordereis, E. (2009). Gender differences in views about cognitive health and healthy lifestyle behaviors among rural older adults. The Gerontologist, 49, 572-578. Doi:10.1093/geront/gnp077

Yun, R.J., \& Lachman, M.E. (2006). Perceptions of aging in two cultures: Korean and American views on old age. Journal of Cross Cultural Gerontology, 21, 55-70.

Doi:10.1007/s10823-006-9018-y 
Table 1.

Means and Standard Deviations Among Demographic Characteristics and Main Study

Variables

\begin{tabular}{|c|c|c|}
\hline \multicolumn{3}{|l|}{ Measure } \\
\hline & $M$ & $S D$ \\
\hline Age & 53.49 & 14.19 \\
\hline Perceived Health & 3.18 & .50 \\
\hline Preferences to Make Decisions & 2.98 & .87 \\
\hline Alone & & \\
\hline $\begin{array}{l}\text { Preferences to Make Decisions } \\
\text { with Others }\end{array}$ & & \\
\hline Perceived Ability to Make & 1.47 & .53 \\
\hline $\begin{array}{l}\text { Decisions as One has Gotten } \\
\text { Older }\end{array}$ & & \\
\hline $\begin{array}{l}\text { Perceived Ability to Make } \\
\text { decisions as Compared to } \\
\text { Same-Aged Peers }\end{array}$ & 1.54 & .50 \\
\hline \multirow{2}{*}{$\begin{array}{l}\text { Perceived Benefits of Aging in } \\
\text { Decision-Making }\end{array}$} & 3.71 & .67 \\
\hline & $\mathrm{n}$ & $(\%)$ \\
\hline \multicolumn{3}{|l|}{ Gender } \\
\hline Female & 604 & $(56.2)$ \\
\hline Male & 471 & $(43.8)$ \\
\hline \multicolumn{3}{|l|}{ Race } \\
\hline White & 910 & $(84.7)$ \\
\hline Black & 85 & $(7.9)$ \\
\hline Asian & 24 & $(2.2)$ \\
\hline Native Am. & 7 & $(0.7)$ \\
\hline Other & 46 & $(4.3)$ \\
\hline Not reported & 3 & $(0.2)$ \\
\hline \multicolumn{3}{|l|}{ Hispanic/Latino } \\
\hline Yes & 91 & $(8.5)$ \\
\hline No & 982 & $(91.5)$ \\
\hline \multicolumn{3}{|l|}{ Education } \\
\hline Less than HS & 6 & $(0.6)$ \\
\hline Some High School & 24 & $(2.2)$ \\
\hline High School Grad & 151 & $(14.0)$ \\
\hline Vocational Training & 67 & $(6.2)$ \\
\hline Some College & 251 & $(23.3)$ \\
\hline Associate Degree & 69 & $(6.4)$ \\
\hline Bachelor's Degree & 292 & $(27.2)$ \\
\hline Master's Degree & 163 & $(15.2)$ \\
\hline Ph.D./Professional & 52 & $(4.8)$ \\
\hline
\end{tabular}


Never married

Married/living with partner

Separated

Divorced

Widowed
165

659

18

169

64
(15.3)

$(61.3)$

(1.7)

$(15.7)$

(6.0) 
Table 2.

Bivariate Correlations Among Demographic Characteristics and Main Study Variables using Spearman's Rho

\begin{tabular}{|c|c|c|c|c|c|c|c|c|}
\hline & Age & Gender & $\begin{array}{l}\text { Perceived } \\
\text { health }\end{array}$ & $\begin{array}{l}\text { Preferences to } \\
\text { make } \\
\text { decisions } \\
\text { alone }\end{array}$ & $\begin{array}{l}\text { Preferences } \\
\text { to make } \\
\text { decisions } \\
\text { with others }\end{array}$ & $\begin{array}{l}\text { Perceived ability } \\
\text { to make decisions } \\
\text { as one has gotten } \\
\text { older }\end{array}$ & $\begin{array}{l}\text { Perceived } \\
\text { ability to make } \\
\text { decisions as } \\
\text { compared to } \\
\text { same-aged } \\
\text { peers }\end{array}$ & $\begin{array}{l}\text { Perceived } \\
\text { benefits of } \\
\text { aging in } \\
\text { decision- } \\
\text { making }\end{array}$ \\
\hline Age & ---- & $-.13 * * *$ & -.01 & $.09 * *$ & $-.12 * * *$ & $-.30 * * *$ & -.05 & .04 \\
\hline Gender & & ---- & -.02 & -.02 & -.04 & .02 & $-.12 * * *$ & -.04 \\
\hline Perceived health & & & $\begin{array}{ll}--- \\
\end{array}$ & .01 & .03 & $.20 * * *$ & $.22 * * *$ & .01 \\
\hline $\begin{array}{l}\text { Preferences to } \\
\text { make decisions } \\
\text { alone }\end{array}$ & & & & $\begin{array}{ll}--- \\
\end{array}$ & $-.54 * * *$ & .04 & $.10 * *$ & $.06^{*}$ \\
\hline $\begin{array}{l}\text { Preferences to } \\
\text { make decisions } \\
\text { with others }\end{array}$ & & & & & ---- & $.11 * * *$ & -.02 & $.11 * * *$ \\
\hline $\begin{array}{l}\text { Perceived ability } \\
\text { to make } \\
\text { decisions as one } \\
\text { has gotten older }\end{array}$ & & & & & & ---- & $.40 * * *$ & $.08 *$ \\
\hline $\begin{array}{l}\text { Perceived ability } \\
\text { to make } \\
\text { decisions as } \\
\text { compared to } \\
\text { same-aged peers }\end{array}$ & & & & & & & ---- & .04 \\
\hline $\begin{array}{l}\text { Perceived } \\
\text { benefits of aging } \\
\text { in decision- } \\
\text { making }\end{array}$ & & & & & & & & ---- \\
\hline
\end{tabular}

Note. ${ }^{*} \mathrm{p} \leq .05 .{ }^{* *} \mathrm{p} \leq .01 .{ }^{* *} \mathrm{p} \leq .001$. 
Table 3.

Regression Analysis Summary for Variables Predicting Perceived Ability to Make Decisions as One Has Gotten Older and as Compared to Same-Aged Peers $\mid$

\begin{tabular}{|l|l|l|l|l|l|l|l|l|l|l|}
\hline & \multicolumn{4}{|l|}{$\begin{array}{l}\text { Perceived Ability to Make } \\
\text { Decisions as One Has Gotten } \\
\text { Older }\end{array}$} & \multicolumn{3}{l}{$\begin{array}{l}\text { Perceived Ability to Make Decisions } \\
\text { as Compared to Same-Aged Peers }\end{array}$} \\
\hline Variable & $\boldsymbol{B}$ & $\begin{array}{l}\boldsymbol{S} \boldsymbol{E} \\
\boldsymbol{B}\end{array}$ & $\boldsymbol{\beta}$ & $\boldsymbol{t}$ & $\boldsymbol{p}$ & $\boldsymbol{B}$ & $\boldsymbol{S} \boldsymbol{E} \boldsymbol{B}$ & $\boldsymbol{\beta}$ & $\boldsymbol{t}$ & $\boldsymbol{p}$ \\
\hline Perceived Health & .06 & .01 & .20 & 7.01 & .000 & .06 & .01 & .23 & 7.86 & .000 \\
\hline Age & -.01 & .00 & -.30 & -10.26 & .000 & -.00 & .01 & -.07 & -2.30 & .022 \\
\hline Gender & -.01 & .03 & -.01 & -.29 & .771 & -.11 & .03 & -.12 & -3.87 & .000 \\
\hline Age X Gender & .00 & .00 & .01 & .12 & .908 & .00 & .00 & -.02 & -.23 & .820 \\
\hline
\end{tabular}


Table 4.

Regression Analysis Summary for Variables Predicting Preferences to Make Decisions Alone and with Others

\begin{tabular}{|c|c|c|c|c|c|c|c|c|c|c|}
\hline \multirow[b]{2}{*}{ Variable } & \multicolumn{5}{|c|}{$\begin{array}{l}\text { Preference to Make Decisions } \\
\text { Alone }\end{array}$} & \multicolumn{5}{|c|}{$\begin{array}{l}\text { Preference to Make Decisions with } \\
\text { Others }\end{array}$} \\
\hline & $B$ & $\begin{array}{l}S E \\
B\end{array}$ & $\beta$ & $t$ & $p$ & $B$ & $S E B$ & $\beta$ & $t$ & $p$ \\
\hline Perceived Health & -.03 & .05 & -.02 & -.65 & .517 & .04 & .05 & .03 & .92 & .360 \\
\hline Age & .02 & .01 & .12 & 3.80 & .000 & -.02 & .01 & -.12 & -3.88 & .000 \\
\hline Gender & .01 & .16 & .00 & .07 & .942 & -.32 & .16 & -.06 & -2.02 & .044 \\
\hline $\begin{array}{l}\text { Perceived Benefits } \\
\text { of Aging in } \\
\text { Decision-Making }\end{array}$ & .03 & .02 & .04 & 1.33 & .183 & .08 & .02 & .10 & 3.45 & .001 \\
\hline $\begin{array}{l}\text { Perceived Ability } \\
\text { to Make Decisions } \\
\text { as One has Gotten } \\
\text { Older }\end{array}$ & .20 & .17 & .04 & 1.19 & .236 & .47 & .17 & .10 & 2.77 & .006 \\
\hline $\begin{array}{l}\text { Perceived Ability } \\
\text { to Make decisions } \\
\text { as Compared to } \\
\text { Same-Aged Peers }\end{array}$ & .51 & .18 & .10 & 2.86 & .004 & -.48 & .18 & -.09 & 3.37 & .001 \\
\hline
\end{tabular}

Note. Preference for making decisions alone, $\mathrm{R}^{2}=.03(\mathrm{~N}=1075, p<.001)$; Preference for making decisions with others, $\mathrm{R}^{2}=.04(\mathrm{~N}=1075, p<.001)$. 
Table 5.

Indirect Effect Analysis Summary for Variables Predicting Preferences to Make Decisions Alone and with Others

\begin{tabular}{|c|c|c|c|c|c|c|c|c|}
\hline \multirow[b]{2}{*}{ Mediator } & \multicolumn{4}{|c|}{$\begin{array}{l}\text { Preference to Make Decisions } \\
\text { Alone }\end{array}$} & \multicolumn{4}{|c|}{$\begin{array}{l}\text { Preference to Make Decisions } \\
\text { with Others }\end{array}$} \\
\hline & $B$ & $S E B$ & $L L C I$ & $U L C I$ & $\boldsymbol{B}$ & $S E B$ & $L L C I$ & $U L C I$ \\
\hline $\begin{array}{l}\text { Perceived Ability } \\
\text { to Make } \\
\text { decisions as } \\
\text { Compared to } \\
\text { Same-Aged Peers }\end{array}$ & -.0014 & .0008 & -.0032 & -.001 & .0011 & .0007 & .0000 & .0026 \\
\hline $\begin{array}{l}\text { Perceived Ability } \\
\text { to Make } \\
\text { Decisions as One } \\
\text { has Gotten Older }\end{array}$ & & & & & -.0052 & .0020 & -.0092 & -.0015 \\
\hline $\begin{array}{l}\text { Perceived } \\
\text { Benefits of Aging } \\
\text { in Decision- } \\
\text { Making }\end{array}$ & & & & & .0006 & .0006 & -.0005 & .0020 \\
\hline $\begin{array}{l}\text { Total Indirect } \\
\text { Effect }\end{array}$ & & & & & -.0035 & .0020 & -.0074 & .0004 \\
\hline
\end{tabular}




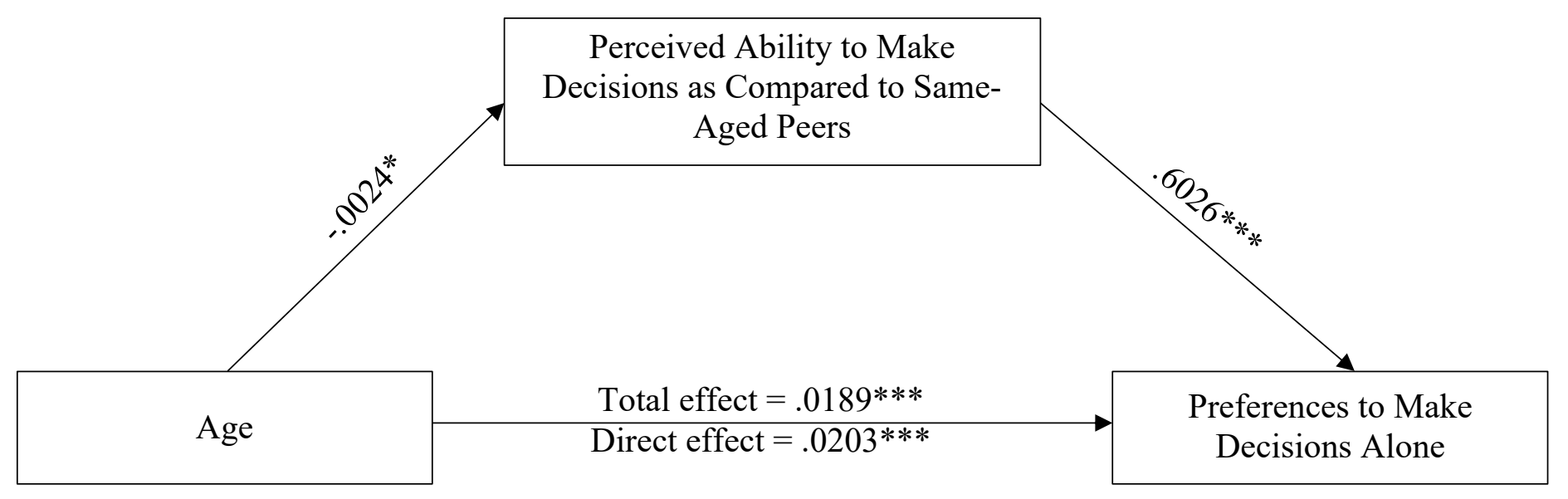

Figure 1. Model for Research Question 5 examining the indirect effects of perceived ability to make decisions as compared to same-aged peers on the association between age and preferences to make decisions alone, while controlling for perceived health and gender. ${ }^{*} \mathrm{p}<.05$. ${ }^{*} \mathrm{p}<.01$. $* * * \mathrm{p}<.001$. 


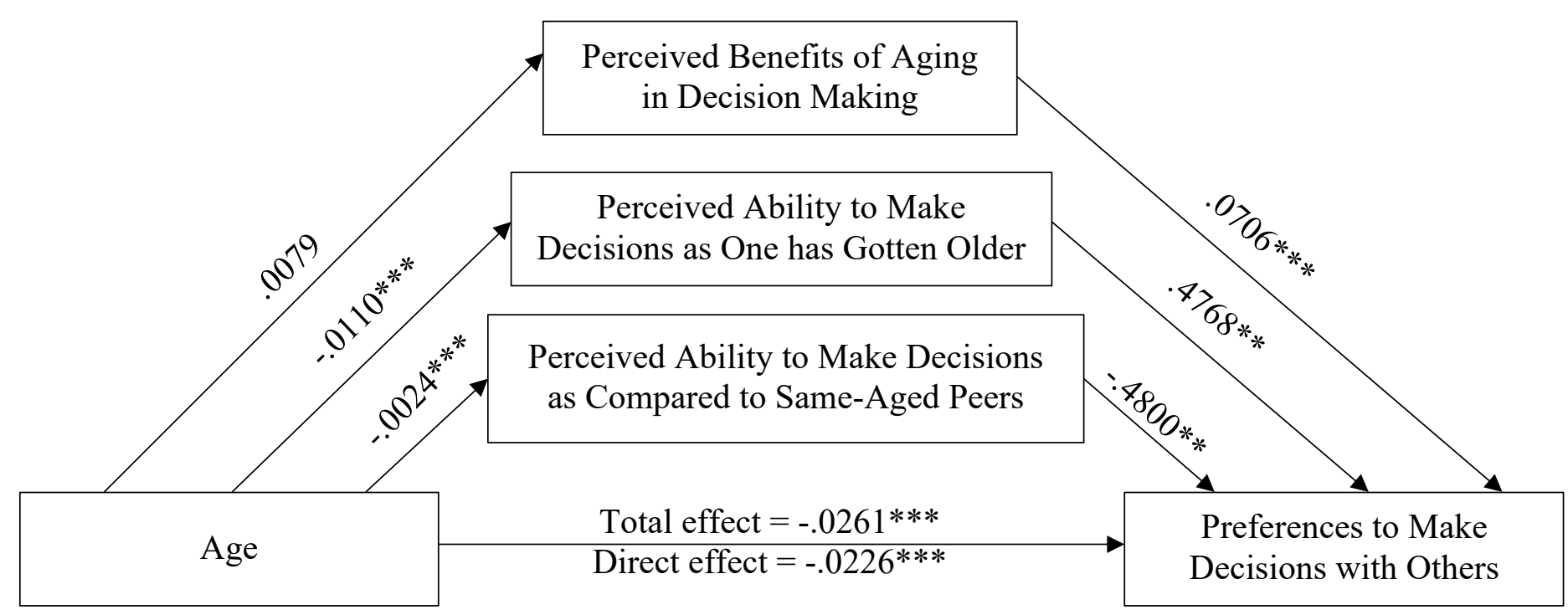

Figure 2. Model for Research Question 5 examining the indirect effects of perceived benefits of aging in decision making, perceived ability to make decisions as one has gotten older, and perceived ability to make decisions as compared to same-aged peers on the association between age and preferences to make decisions with others, while controlling for perceived health and gender. ${ }^{*} \mathrm{p}<.05 . * * \mathrm{p}<.01 . * * * \mathrm{p}<.001$. 


\section{Appendix A}

Decision-Making Preferences (Self v. Other). Adapted from Strough et al (2002). Original wording "solve problems" replaced with "make decisions".

When making decisions in your everyday life, do you prefer to work alone?
Do Not Prefer
2
3
4
5
Very Much Prefer

When making decisions in your everyday life, do you prefer to work with other people?
Do Not Prefer
2
3
5
Very Much Prefer

How often do you work with other people to make decisions?

1
Never 2

3

How often do you work alone to make decisions?

1
Never

2

3

4

5

Very Often

How much do you like working with others to make decisions?

Do Not Like

2

3

4

5

Like Very Much

How much do you like working alone to make decisions?

$1 \quad 2$

3

Do Not Like
2
4

(1)

(1)
Very Often 


\section{Appendix B}

Perceived Ability - Temporal Comparisons. Adapted from Strough et al (2002). Original wording "solve problems" replaced with "make decisions" decisions about self v. other added.

INSTRUCTIONS

As they age, some people notice changes in their ability to make decisions. Please answer the following items about how you view your ability to make decisions in light of your own aging.

As I have gotten older, my ability to make decisions is:

Better

The Same

Not as good

As I have gotten older, my ability to make decisions about things that affect other people is:

Better

The Same

Not as good

As I have gotten older, my ability to make decisions about things that affect only me is:

Better

The Same

Not as good 


\section{Appendix C}

Perceived Ability - Social Comparisons. Adapted from Strough et al (2002). Original wording "solve problems" replaced with "make decisions" decisions about self $\mathrm{v}$. other added.

Compared with most people your age, would you say your ability to make decisions is:

Better

The Same

Not as good

Compared with most people your age, would you say your ability to make decisions that affect only you is:

\section{Better}

The Same

Not as good

Compared with most people your age, would you say your ability to make decisions that affect other people is:

\section{Better}

The Same

Not as good 


\section{Appendix D}

Beliefs about aging and decision making. These items get at perceptions of how decision making changes with age.

\section{INSTRUCTIONS}

Please answer the following items about how people make decisions:

1. Experience comes with age.

$\begin{array}{ccccc}1 & 2 & 3 & 4 & 5 \\ \text { Strongly } & & & & \text { Strongly } \\ \text { Disagree } & & & \text { Agree }\end{array}$

2. In old age, people make more rational decisions.

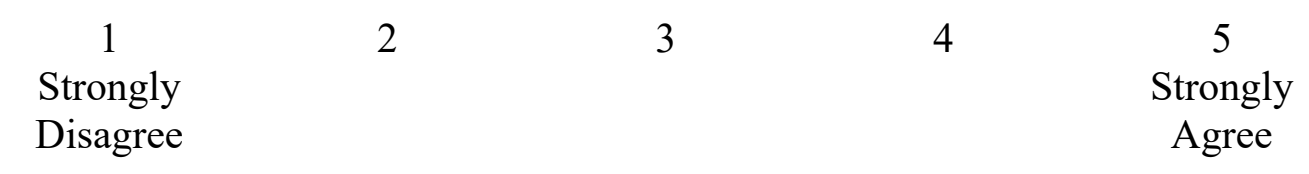

3. In old age, people have better intuitions or gut feelings about the best choice.

$\begin{array}{ccccc}1 & 2 & 3 & 4 & 5 \\ \text { Strongly } & & & & \text { Strongly } \\ \text { Disagree } & & & & \text { Agree }\end{array}$

4. People with more experience make more rational decisions.

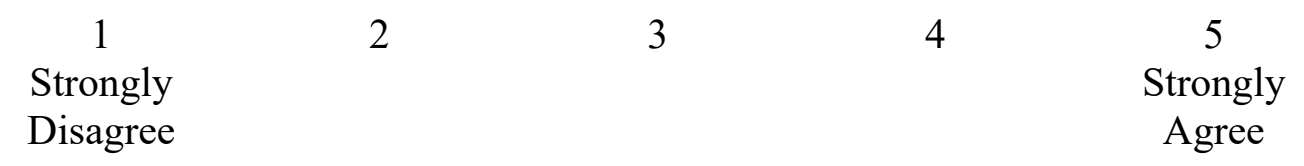

5. People with more experience have better intuitions or gut feelings about the best choice.

$\begin{array}{ccccc}1 & 2 & 3 & 4 & 5 \\ \text { Strongly } & & & & \text { Strongly } \\ \text { Disagree } & & & \text { Agree }\end{array}$

6. In old age, people have greater self-control.

$\begin{array}{ccccc}1 & 2 & 3 & 4 & 5 \\ \text { Strongly } & & & \text { Strongly } \\ \text { Disagree } & & & \text { Agree }\end{array}$


7. In old age, people have a harder time thinking through decision options and consequences.

$\begin{array}{ccccc}1 & 2 & 3 & 4 & 5 \\ \text { Strongly } & & & & \text { Strongly } \\ \text { Disagree } & & & \text { Agree }\end{array}$

8. Time becomes more valuable as people get older.

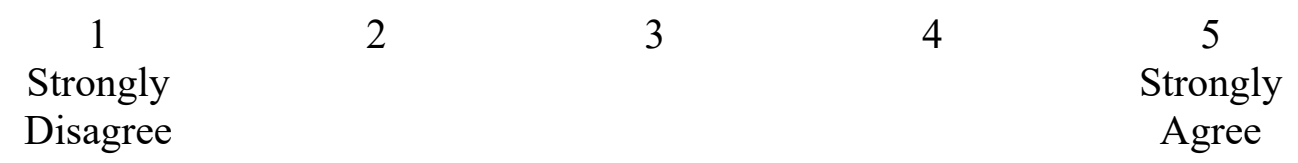

9. The number of things that really matters gets smaller as people get older.

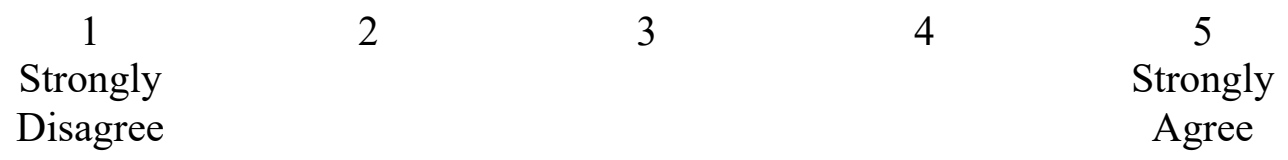




\section{Appendix E: Exploratory Factor Analysis}

An exploratory factor analysis was first conducted of the beliefs about aging and decision-making items (see Appendix Table 1). The purpose of this analysis was to determine the validity and reliability of this brand new measure created for this research study. The scree plot indicated three factors with initial eigenvalues that exceeded 1.0 (specifically, 3.14, 1.13, and 1.09). After direct oblimin rotation (allowing the factors to be correlated), the three factors accounted for $34.87 \%, 12.59 \%$, and $12.11 \%$ of the variance, respectively.

The first factor was labeled 'benefits of aging for decision making.' Each of the five items in this factor included phrasing that framed aging as a positive attribute when making decisions. The items that loaded the highest on this factor were 'people with more experience have better intuitions or gut feelings about the best choice,' followed by 'people with more experience make more rational decisions' and 'in old age, people have better intuitions or gut feelings about the best choice.' A benefits of aging in decision making score was computed that was the average of the five items that loaded on the first factor. None of the items were reverse scored. The internal consistency of the scale was acceptable, $\alpha=.783($ range $=1-5, M=3.71, S D=.67)$.

The second factor contained two items, and the third factor contained two items. One item cross-loaded on the first factor and the third factor. Due to the cross-loading and the low values of each loading $(<.5$ for both), the item was eliminated. Because both the second and third factors each only contained two items, because they were both just slightly over a 1.0 eigenvalue, and because neither factor had a unifying or comprehensible theme, the items they contained were eliminated. Additionally, the internal consistencies of these two factors were low ( $\alpha=.315, \alpha=-.518$, respectively) Using only the perceived benefits of aging in decision making 
scale, the internal consistency improved from .670 with the original nine items to .783 with the five item perceived benefits scale. 


\section{Appendix F: Benefits of Aging in Decision Making Scale}

Benefits of aging in decision making. These items get at perceptions of how decision making changes with age.

INSTRUCTIONS

Please answer the following items about how people make decisions:

1. Experience comes with age.

$\begin{array}{ccccc}1 & 2 & 3 & 4 & 5 \\ \text { Strongly } & & & & \text { Strongly } \\ \text { Disagree } & & & \text { Agree }\end{array}$

2. In old age, people make more rational decisions.

$\begin{array}{ccccc}1 & 2 & 3 & 4 & 5 \\ \text { Strongly } & & & & \text { Strongly } \\ \text { Disagree } & & & \text { Agree }\end{array}$

3. In old age, people have better intuitions or gut feelings about the best choice.

$\begin{array}{ccccc}1 & 2 & 3 & 4 & 5 \\ \text { Strongly } & & & & \text { Strongly } \\ \text { Disagree } & & & \text { Agree }\end{array}$

4. People with more experience make more rational decisions.

$\begin{array}{ccccc}1 & 2 & 3 & 4 & 5 \\ \text { Strongly } & & & & \text { Strongly } \\ \text { Disagree } & & & & \text { Agree }\end{array}$

5. People with more experience have better intuitions or gut feelings about the best choice.

1

Strongly

Disagree
2
4

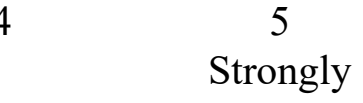

5

Agree 


\section{Appendix Table 1.}

Direct Oblimin Pattern Matrix of Rotated Factor Loadings from an Exploratory Factor Analysis of Beliefs about Aging and Decision-Making Items

\begin{tabular}{|c|c|c|c|}
\hline Item & $\begin{array}{l}\text { Factor 1: Benefits } \\
\text { of Aging for } \\
\text { Decision Making }\end{array}$ & Factor 2 & Factor 3 \\
\hline 1. Experience comes with age. & .59 & -.16 & .06 \\
\hline $\begin{array}{l}\text { 2. In old age, people make more } \\
\text { rational decisions. }\end{array}$ & .66 & .09 & .37 \\
\hline $\begin{array}{l}\text { 3. In old age, people have better } \\
\text { intuitions or gut feelings about } \\
\text { the best choice. }\end{array}$ & .71 & .04 & .21 \\
\hline $\begin{array}{l}\text { 4. People with more experience } \\
\text { make more rational decisions. }\end{array}$ & .78 & -.02 & -.17 \\
\hline $\begin{array}{l}\text { 5. People with more experience } \\
\text { have better intuitions or gut } \\
\text { feelings about the best choice. }\end{array}$ & .82 & .03 & -.29 \\
\hline $\begin{array}{l}\text { 6. In old age, people have better } \\
\text { self-control. }\end{array}$ & .41 & -.18 & .43 \\
\hline $\begin{array}{l}\text { 7. In old age, people have a } \\
\text { harder time thinking through } \\
\text { decision options and } \\
\text { consequences. }\end{array}$ & -.10 & .03 & .86 \\
\hline $\begin{array}{l}\text { 8. Time becomes more valuable } \\
\text { as people get older. }\end{array}$ & .18 & -.67 & .02 \\
\hline $\begin{array}{l}\text { 9. The number of things that } \\
\text { really matters gets smaller as } \\
\text { people get older. }\end{array}$ & .16 & .86 & .03 \\
\hline
\end{tabular}

Note. The highest loading for each item is shown in bold. 